\title{
Association between posterior fossa arteriovenous malformations and prenidal aneurysm rupture: potential impact on management
}

\author{
Evgueni Kouznetsov, M.D., F.R.C.S., Alain Weill, M.D., F.R.C.P., \\ Jimmy S. Ghostine, M.D., F.R.C.P., Jean-Christophe Gentric, M.D., \\ Jean RaYmond, M.D., F.R.C.P., and DaniEl Roy, M.D., F.R.C.P. \\ Department of Radiology, CHUM, Montréal, Québec, Canada
}

\begin{abstract}
Object. In patients with posterior fossa arteriovenous malformations (AVMs) who present with hemorrhage, feeding artery aneurysms are often the source of bleeding. The aim of this study was to evaluate the relative proportions of cases of infra- and supratentorial AVMs in which patients presented with prenidal aneurysm rupture. The management and outcome of 9 cases of posterior fossa AVMs associated with prenidal aneurysm rupture are presented.

Methods. The authors retrospectively reviewed 233 consecutive AVM cases involving patients treated at their institution between April 2001 and August 2012. Patients with a prenidal aneurysm as the cause of the hemorrhage were identified. The frequencies of prenidal aneurysm-related ruptures were compared in cases of supra- and infratentorial AVMs. Management and clinical outcome (modified Rankin Scale [mRS] score) of patients with posterior fossa AVMs treated for ruptured prenidal aneurysms were recorded.

Results. Of 233 AVMs, $25(11 \%)$ were in the posterior fossa, and in $22(88 \%)$ of these cases, the patients presented with hemorrhage, including 9 patients $(41 \%)$ who presented with hemorrhage due to prenidal aneurysm rupture. Of 208 patients with supratentorial AVMs, 107 (51\%) presented with hemorrhage, including 5 patients $(4.7 \%)$ in whom the hemorrhage was associated with a prenidal aneurysm $(\mathrm{p}<0.01)$. All 9 patients with posterior fossa AVMs and prenidal aneurysm rupture were treated with early embolization of the offending aneurysm. There was no early rebleeding or clinical complication related to this approach. At the end of follow-up (mean 46.8 months), 2 patients had an mRS score of 0,1 had a score of 1,3 had a score of 2,2 patients were dead (mRS score of 6), and 1 patient was lost to follow-up.

Conclusions. Posterior fossa AVM hemorrhages are frequently associated with prenidal arterial aneurysms. Urgent endovascular treatment of the aneurysm was effective in this case series. (http://thejns.org/doi/abs/10.3171/2014.6.FOCUS14219)
\end{abstract}

$\begin{array}{lccccc}\text { KEY WORDS } & \text { arteriovenous malformation } & \bullet & \text { cerebral AVM } & \bullet & \text { embolization } \\ \text { prenidal aneurysm } & \bullet & \text { posterior fossa AVM }\end{array}$

$\mathrm{R}$ UPTURED cerebral arteriovenous malformations (AVMs) are associated with significant morbidity and mortality. ${ }^{1,3,4} \mathrm{Up}$ to $18 \%$ of patients with bleeding AVMs harbor associated arterial aneurysms, approximately half of which occur on feeding arteries (prenidal aneurysms). ${ }^{5}$ Numerous reports have suggested a correlation between AVM-related aneurysms and hemorrhage risk. ${ }^{9-11}$ Some authors have previously noticed that prenidal aneurysm ruptures were frequent when AVMs were located in the posterior fossa. ${ }^{2,8,12}$ We sought to confirm, in a series of cases involving patients with AVMs who were treated at our institution, that patients with posterior fossa AVMs frequently present with hemorrhage associated with prenidal aneurysm ruptures. We also aimed to review the outcome for patients presenting with such ruptures who were treated by endovascular means.

\footnotetext{
Abbreviations used in this paper: $\mathrm{AVM}=$ arteriovenous malformation; $\mathrm{mRS}=$ modified Rankin Scale; PICA = posterior inferior cerebellar artery.
}

\section{Methods}

We conducted a retrospective chart and imaging review of all consecutive cases of AVMs in which patients were treated by means of endovascular techniques in our institution between April 2001 and August 2012. This study was approved by our local ethics committee. Patients were included if their neuroradiology reports (angiography and CT) mentioned hemorrhage and the presence of a prenidal aneurysm. Neuroimaging studies were reviewed by a senior neuroradiologist (D.R.). By definition, hemorrhage secondary to the rupture of a prenidal aneurysm was diagnosed when the hematoma and/or the epicenter of subarachnoid hemorrhage was clearly remote from the AVM nidus but in the vicinity of the aneurysm (Fig. 1). Cases in which hemorrhage could be related to an aneurysm located at the circle of Willis or at usual locations in the posterior circulation were excluded. Using this definition, we recorded posterior fossa AVMs that bled from prenidal aneurysms and looked for cases in which 


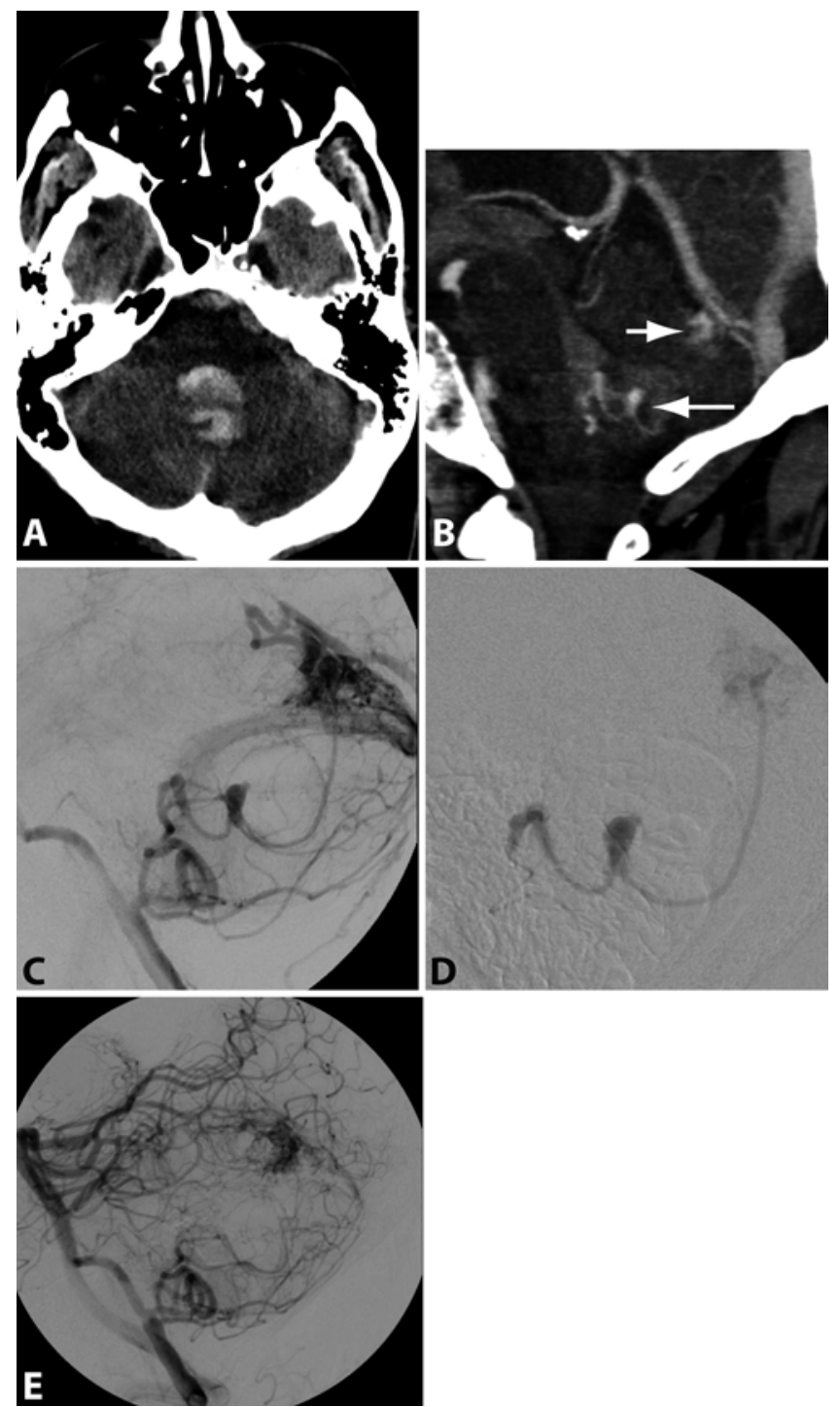

FIG. 1. A: CT scan showing inferior vermian hematoma with blood inside the fourth ventricle. B: CT angiogram (sagittal view) showing AVM feeding artery aneurysm in the epicenter of a hematoma (long arrow) with the AVM nidus (short arrow) clearly remote from the hematoma. C: Left vertebral artery angiogram, lateral view, confirming the CT angiography findings. D: Superselective injection of the PICA branch harboring the aneurysm. E: Left vertebral injection after glue embolization of the aneurysm and parent vessel.

the patients had a similar presentation but had supratentorial AVMs. Proportions were compared using the Z-test. Finally, we report the outcome (modified Rankin Scale [mRS] score) for patients with posterior fossa AVMs presenting with prenidal aneurysm rupture and treated with endovascular embolization.

\section{Results \\ Presentation and Incidence of Prenidal Aneurysm Rupture}

We identified 233 cases of AVMs involving patients treated between April 2001 and August 2012 in our insti- tution. The patients' mean age was 44 years (range $11-80$ years). Of the 233 AVMs, 208 were supratentorial (89\%), and $25(11 \%)$ were located in the posterior fossa. Hemorrhage occurred in $107(51.4 \%)$ of the supratentorial AVMs compared with $22(88 \%)$ of the 25 posterior fossa AVMs. In $9(41 \%)$ of the 22 cases of posterior fossa AVMs, the patients presented with a hemorrhage related to a prenidal aneurysm, whereas only $5(4.7 \%)$ of 107 patients with supratentorial AVMs presented with a prenidal aneurysm hemorrhage $(\mathrm{p}<0.01)$. These data are summarized in Table 1.

\section{Management and Outcome}

The patients' age, AVM and aneurysm characteristics, treatment, and mRS scores are summarized in Table 2. In all 9 cases of hemorrhage due to prenidal aneurysm rupture, the aneurysm presumed responsible for the hemorrhage was treated by means of an endovascular approach on an emergency basis with either coils (5 aneurysms) or glue (4 cases). In most cases (7), the aneurysm was occluded along with its parent artery. One patient (Case 7) died of the initial hemorrhage. In 2 cases, parent vessel occlusion caused a small vermian infarct, with only transient symptoms, if any. There was no permanent neurological complication related to the treatment of prenidal aneurysms. In the 8 surviving patients, 3 unruptured prenidal aneurysms (2 in Case 9, 1 in Case 2) and 1 unruptured posterior inferior cerebellar artery (PICA) aneurysm (in Case 4) were treated electively after the acute phase. Curative treatment of the AVM itself, proven by angiography, was performed on an elective basis in 3 cases (all with embolization followed by resection). One patient (Case 9) was treated the following month, and the other 2 (Cases 4 and 6) were treated 5 months and 20 months, respectively, after the initial hemorrhage, when clinical recovery was optimal. In the remaining 6 patients, the AVM nidus was left untreated: 1 patient (Case 7) died of initial hemorrhage; 1 patient, who was 76 years old at presentation (Case 3), was lost to follow-up; and 4 patients declined definitive treatment of the AVM. One of these patients who declined definitive AVM treatment died 4 years later from AVM rupture (Case 5). The mean follow-up period of the 6 surviving and followed patients was 46.8 months (range 19-74 months). At the end of follow-up, 6 of 9 patients had a good outcome. The mRS score was 0 in 2 cases, 1 in 1 case, 2 in 3 cases, 6 in 2 cases, and 1 patient was lost to follow-up.

TABLE 1: Proportion of bleeding AVMs with prenidal aneurysm rupture

\begin{tabular}{lccc}
\hline AVM Location & $\begin{array}{c}\text { Total No. } \\
\text { of AVMs }\end{array}$ & $\begin{array}{c}\text { AVMs wl } \\
\text { Hemorrhagic } \\
\text { Presentation }\end{array}$ & $\begin{array}{c}\text { Hemorrhage Due } \\
\text { to Prenidal Aneurysm } \\
\text { Rupture* }\end{array}$ \\
\hline $\begin{array}{l}\text { supratentorial } \\
\text { infratentorial }\end{array}$ & 208 & $107(51.4 \%)$ & $5(4.7 \%)$ \\
\hline * Percentages calculated based on number of AVMs with hemorrhagic \\
presentation.
\end{tabular}




\section{Management of prenidal aneurysm rupture in posterior fossa AVMs}

TABLE 2: AVM characteristics, management, and clinical outcomes in patients with posterior fossa AVM and prenidal aneurysm rupture*

\begin{tabular}{|c|c|c|c|c|c|c|c|c|c|}
\hline $\begin{array}{l}\text { Case } \\
\text { No. }\end{array}$ & $\begin{array}{l}\text { Pt Age } \\
\text { (yrs) }\end{array}$ & $\begin{array}{l}\text { AVM Size } \\
(\mathrm{cm})\end{array}$ & AVM Location & $\begin{array}{l}\text { Aneurysm } \\
\text { Size }(\mathrm{mm})\end{array}$ & $\begin{array}{c}\text { Aneurysm } \\
\text { Location }\end{array}$ & Treatment & Complication & $\begin{array}{l}\text { AVM Nidus } \\
\text { Treatment }\end{array}$ & Outcome \\
\hline 1 & 58 & 3.0 & $\begin{array}{c}\text { superficial right } \\
\text { hemisphere }\end{array}$ & 10 & right PICA & PVO coils & infarct, asymptomatic & no & 43 mos, mRS 0 \\
\hline 2 & 57 & 2.5 & $\begin{array}{c}\text { superficial right } \\
\text { hemisphere }\end{array}$ & 4 & right PICA & PVO glue & infarct, asymptomatic & no & 51 mos, mRS 1 \\
\hline 3 & 76 & 1.5 & superior vermis & 10 & right SCA & PVO coils & none & no & lost to follow-up \\
\hline 4 & 48 & 2.5 & $\begin{array}{c}\text { superficial right } \\
\text { hemisphere }\end{array}$ & 6 & left SCA & selective coils & none & yes & 23 mos, mRS 2 \\
\hline 5 & 58 & 1.7 & superior vermis & 5 & left SCA & PVO coils & none & no & $\begin{array}{l}\text { hemorrhage } 4 \text { yrs la- } \\
\text { ter, mRS } 6\end{array}$ \\
\hline 6 & 21 & 2.4 & superior vermis & 3 & right SCA & PVO glue & none & yes & 19 mos, mRS 2 \\
\hline 7 & 62 & 1.3 & superior vermis & 13 & left SCA & selective coils & none & no & mRS 6, acute phase \\
\hline 8 & 63 & 1.7 & superior vermis & 5 & left PICA & PVO glue & none & no & 74 mos, mRS 0 \\
\hline 9 & 45 & 3.1 & superior vermis & $\begin{array}{l}\text { multiple aneu- } \\
\text { rysms }\end{array}$ & left PICA & PVO glue & none & yes & 71 mos, mRS 2 \\
\hline
\end{tabular}

* $\mathrm{mRS}=$ modified Rankin Scale score; PICA = posterior inferior cerebellar artery; pt = patient; $\mathrm{PVO}$ = parent vessel occlusion; $\mathrm{SCA}=$ superior cerebellar artery.

\section{Discussion}

We present a retrospective study, showing that patients with posterior fossa AVMs frequently presented with prenidal aneurysm rupture. The occurrence of hemorrhagic presentation with the hematoma or hemorrhage center close to a prenidal arterial aneurysm and remote from the AVM nidus was more frequent in patients with posterior fossa AVMs than in those with supratentorial AVMs (41\% vs $4.7 \%$ ) in our patient population.

Westphal and Grzyska ${ }^{12}$ also reported that feeding vessel aneurysms occur more frequently in association with infratentorial than supratentorial AVMs. In the series reported by Schmidt et al.. ${ }^{8} 30 \%$ of posterior fossa AVMs versus $11 \%$ of supratentorial AVMs were associated with aneurysms (on feeding vessels within the nidus). The main difference concerned the feeding artery aneurysms (25\% vs 5\%). Associated aneurysms were the source of bleeding in $10.5 \%$ of cases of infratentorial AVMs but only $1.7 \%$ of cases of supratentorial AVMs. ${ }^{8}$ In the series of posterior fossa AVMs reported by da Costa et al.,. ${ }^{2}$ the presence of associated aneurysms was associated with worse outcomes.

We acknowledge multiple weaknesses in this study. This is not a natural history study, since only treated patients who had at least 1 endovascular treatment were registered and reviewed. Patients were often referred from other centers, and reasons for referrals and indications for treatments have undoubtedly biased numbers. A systematic imaging protocol was not followed, and not all patients presenting with hemorrhage had an early angiogram to specifically look for aneurysms. We found an almost 10fold difference between supratentorial and infratentorial AVMs, with respect to the presence of ruptured prenidal aneurysms ( $41 \%$ vs $4.7 \%)$. This difference may be related to an apparent increased "fragility" that has been evoked in hemorrhagic dissections and nonmycotic distal aneurysms. ${ }^{6,7}$
Knowledge of this tendency in posterior fossa AVMs may be useful for the early management of these cases given that the associated aneurysms are often easier to treat definitively than the AVMs themselves. This may be especially true should the AVM be associated with a higher treatment risk due to its location size or patient's factors.

The frequent association of prenidal aneurysms in bleeding posterior fossa AVMs suggests that they should be systematically searched for. We suggest that urgent treatment of the offending aneurysm with embolization may be indicated to prevent early rebleeding, with treatment of the AVM itself being deferred if desirable.

\section{Conclusions}

In patients with posterior fossa AVMs presenting with hemorrhage, the hemorrhage is frequently associated with prenidal arterial aneurysms. Our series and others suggest that this association could be more frequent in patients with posterior fossa AVMs than in those with supratentorial AVMs. Urgent endovascular treatment, most frequently by parent vessel occlusion, was effective in this small series.

\section{Disclosure}

The authors report no conflict of interest concerning the materials or methods used in this study or the findings specified in this paper.

Author contributions to the study and manuscript preparation include the following. Conception and design: Roy, Weill. Acquisition of data: Roy, Kouznetsov. Analysis and interpretation of data: Roy, Kouznetsov, Weill, Ghostine. Drafting the article: Roy, Gentric. Critically revising the article: Ghostine, Raymond. Administrative/ technical/material support: Gentric.

\section{References}

1. Brown RD Jr, Wiebers DO, Forbes G, O'Fallon WM, Piepgras 


\section{E. Kouznetsov et al.}

DG, Marsh WR, et al: The natural history of unruptured intracranial arteriovenous malformations. J Neurosurg 68:352357,1988

2. da Costa L, Thines L, Dehdashti AR, Wallace MC, Willinsky RA, Tymianski M, et al: Management and clinical outcome of posterior fossa arteriovenous malformations: report on a single-centre 15-year experience. J Neurol Neurosurg Psychiatry 80:376-379, 2009

3. da Costa L, Wallace MC, terBrugge KG, O'Kelly C, Willinsky RA, Tymianski M: The natural history and predictive features of hemorrhage from brain arteriovenous malformations. Stroke 40:100-105, 2009

4. Graf CJ, Perret GE, Torner JC: Bleeding from cerebral arteriovenous malformations as part of their natural history. J Neurosurg 58:331-337, 1983

5. Gross BA, Du R: Natural history of cerebral arteriovenous malformations: a meta-analysis. Clinical article. J Neurosurg 118:437-443, 2013

6. Li S, Yan B, Kaye A, Mitchell P, Dowling R, Collins M, et al: Prognosis of intracranial dissection relates to site and presenting features. J Clin Neurosci 18:789-793, 2011

7. Rodríguez-Hernández A, Zador Z, Rodríguez-Mena R, Lawton MT: Distal aneurysms of intracranial arteries: application of numerical nomenclature, predilection for cerebellar arteries, and results of surgical management. World Neurosurg 80: 103-112, 2013

8. Schmidt NO, Reitz M, Raimund F, Treszl A, Grzyska U, Westphal M, et al: Clinical relevance of associated aneurysms with arteriovenous malformations of the posterior fossa. Acta Neurochir Suppl 112:131-135, 2011

9. Stapf C, Mohr JP, Pile-Spellman J, Sciacca RR, Hartmann A,
Schumacher HC, et al: Concurrent arterial aneurysms in brain arteriovenous malformations with haemorrhagic presentation. J Neurol Neurosurg Psychiatry 73:294-298, 2002

10. Stefani MA, Porter PJ, terBrugge KG, Montanera W, Willinsky RA, Wallace MC: Angioarchitectural factors present in brain arteriovenous malformations associated with hemorrhagic presentation. Stroke 33:920-924, 2002

11. Turjman F, Massoud TF, Viñuela F, Sayre JW, Guglielmi G, Duckwiler G: Correlation of the angioarchitectural features of cerebral arteriovenous malformations with clinical presentation of hemorrhage. Neurosurgery 37:856-862, 1995

12. Westphal M, Grzyska U: Clinical significance of pedicle aneurysms on feeding vessels, especially those located in infratentorial arteriovenous malformations. J Neurosurg 92:9951001,2000

Manuscript submitted May 14, 2014.

Accepted June 17, 2014.

This study was presented at the 51st Annual Meeting of the American Society of Neuroradiology (ASNR), May 20-23, 2013, in San Diego, California, and at the 40th Annual Congress of the Société Française de Neuroradiologie (SFNR), April 4-6, 2013, in Paris, France.

Please include this information when citing this paper: DOI: 10.3171/2014.6.FOCUS14219.

Address correspondence to: Daniel Roy, M.D., CHUM Montréal, Neuroradiology, Notre-Dame Hospital, Lachapelle Ward, 1560 Sherbrooke St. E., Montréal, QC H2L 4M1, Canada. email: daniel. roy.chum@ssss.gouv.qc.ca. 